\title{
SCHOLARSHIP PROGRAM FOR TRANSCATHETER TREATMENT OF CONGENITAL HEART DEFECTS AT SILESIAN CENTER FOR HEART DISEASES, ZABRZE, POLAND AND OTHER PLACES FOR FOREIGN INTERVENTIONAL CARDIOLOGIST
}

D01:10.36740/WLek202108140

\author{
Jacek Białkowski ${ }^{1,2}$ \\ 'DEPARTMENT OF CONGENITAL HEART DISEASES AND PEDIATRIC CARDIOLOGY, SILESIAN CENTER FOR HEART DISEASES, ZABRZE, POLAND \\ 2DEPARTMENT OF CONGENITAL HEART DISEASES AND PEDIATRIC CARDIOLOGY, MEDICAL UNIVERSITY OF SILESIA, ZABRZE, POLAND
}

In 2000s I had the pleasure and honor to be invited as a Faculty member at the Pediatric and Adult Interventional Cardiology Symposium (PICS-AICS) organized annually in the USA, as well as the Latin Congress of Pediatric Cardiologists held every two years. There I presented among others ideas a project of training of pediatric interventional cardiologists at the Silesian Center for Heart Diseases in Zabrze, Poland (SCCS) supported by the Friends of Children with Heart Diseases Foundation in Zabrze. In total, 21 cardiologists specializing in interventional treatment of congenital heart defects (CHD) participated in scholarship at our Center in the years 2007-2019. They came from 14 countries: Bolivia, Colombia, Mexico (3 persons), Argentina, Guatemala (Latin America), China, Uzbekistan (Asia), Ukraine (4 persons), Belarus, Russia, Georgia (2 persons), Bulgaria (2 persons), Italy (Europe), and Ruanda (Africa). Their fellowship ranged from 1 to 12 months. With many of the trainees we have prepared several scientific papers [1-12]. Some of this doctors have already been promoted, and have the position of the head of the catheterization laboratory at their hospitals.

In 2007 famous cardiac surgeon dr Aldo Castaneda invited us (me and Prof. M. Szkutnik) to give a lecture on the progress in the transcatheter treatment of CHD at the UNICAR Institute (organized by him in Guatemala City). Somehow the aftermath of our stay in Guatemala was the six-month internship of interventional cardiologist from UNICAR Institute - Dr. Hernan Diaz de Leon, at our Center in 2008. He proved to be a very capable doctor and we enjoyed watching his rapid professional development. The interview entitled 'You live in a happy First World' is especially worth reading and it is related to his stay in Poland (Gazeta Wyborcza, Katowice supplement, December $\left.25^{\text {th }}, 2008\right)$.

In the years 2004-2006 we (with prof. M. Szkutnik) organized and conducted three times training workshops on interventional cardiology in $\mathrm{CHD}$ at the public Obrero Hospital in La Paz situated $3600 \mathrm{~m}$ above sea level (Bolivia). An interesting finding was the discovery of wide patent arterial ducts in high mountain conditions, for which the Amplatzer Duct Occluder type I was best suited [13]. The next step was a multicenter study comparing the characteristics of PDA between patients living in higher areas, namely: Mexico City at $2250 \mathrm{~m}$ above sea level (Instituto Nacional de Cardiologia and Hospital ISSTE, data collected by Dr. Zabal and Dr. Flores), Guatemala City at $1500 \mathrm{~m}$ (UNICAR Institute, data collected by Dr. Diaz de Leon), La Paz (Hospital Obrero, data collected by Dr. Menacho) and lower areas namely: Madrid (Ramona y Cajal Hospital, data collected by Dr. Bermudez-Canete) and Zabrze (SCCS). We collected over 1404 patients: 696 patients from higland and 708 from lowland, the latter group had lower mean pulmonary artery pressure (17.9 vs. $25.5 \mathrm{~mm} \mathrm{Hg}$, $\mathrm{p}<0.001)$ and smaller patent arterial duct diameter ( $2.3 \mathrm{vs.}$ $4.1 \mathrm{~mm}, \mathrm{p}<0.001)$. Probably this is due to the higher oxygen concentration in the air in the lowland [14]. This study was feasible within Interventional Cardiology Working Group of Latin Society of Pediatric Cardiology, of which I was chairman in years 2008-2012.

We performed nonprofit trainings of interventional treatment of CHD in another coutries (mainly invited by our pupils) as in Ucraina, Bulgaria, Uzbekistan, Russia, Czech Rep., Mexico, Cuba. During succeeding 10 years (2009-2019) we were invited also for huge chines congress China Interventional Therapeutics and in the last few years for Mexican CADECI congress, where we performed live cases, too.

Another topic is my initiative to organize catheterization labolatory in Kigali, Ruanda (in Central Africa). I noticed the problem of lack of cath-lab in many African countries and recently I describe my efforts to organize one in $\mathrm{Ru}$ anda [15]. In 2019 we had a pleasure to train in SCCS dr Yves Mutabandama from there. With great satisfaction I received an information that since November 2020 a new catheterization labolatory in the King Faisal Hospital in Kigali has started to work. In my opinion to develop its activity many should be done by international organizations (also Polish) to educate all the medical staff. 


\section{REFERENCES}

1. Cherpak B, Bialkowski J, Szkutnik M. Clinical application of CardioSeal/ Starflex device for closure of ASD, PFO and PDA (abstract). Presented at CSI Congress 7-9.06.2007, Frankfurt, Germany, p. 100.

2. Yashchuk N, Szulik D, Smerdzinski S, et al. Medium- and long-term follow-up of transcatheter closure of ruptured sinus of Valsalva aneurysm: Polish and Ukrainian experience (abstract). Presented at Polish Cardiac Society Congress, Katowice,23.09.2019. Kardiol Pol. 2019;72(suppl. 1):1897-9.

3. Galeczka M, Glowacki J, Yashchuk N, et al. Medium- and long-term follow-up of transcatheter closure of ruptured sinus Valsalva aneurysm in Central Europe population. J Cardiol (Japan) 2019;74(4):381-7.

4. Kusa J, Szkutnik M, Cherpak B, et al. Percutaneous closure of previously surgically treated arterial duct. Eurointervention 2008;3:584-7

5. Fiszer R, Szkutnik M, Yashchuk N, et al. A case of percutaneous modified Blalock-Taussig shunt downsize with multiple stent-in-graft technique. Adv Interv Cardiol 2016;12:164-5.

6. Salas-Llamas JP, Szkutnik M, Fiszer R. Treatment of elevated pulmonary artery pressure in a child after Glenn procedure: transcatheter closure of pulmonary artery banding with subsequent sildenafil therapy. Kardiol Pol. 2012;70:201-3

7. Heredia J, Szkutnik M, Fiszer R Zyla -Frycz M, Bialkowski J. Early neurological complications after transcatheter closure of atrial septal defect with nitinol wire mesh occlude. Kardiol Pol 2013;71:957-9.

8. Heredia J, Szkutnik M, Fiszer R, Serzysko B, Bialkowski J. Use of Amplatzer vascular plug type ll to occluder patent ductus arteriosus in adult patient. Adv Interv Cardiol 2012;8:246-9.

9. Bialkowski J, Szkutnik M, Zhang G, Jiang S. Large coronary fistula and patent ductus arteriosus: transcatheter closure with three nitinol wire mesh occluders. Adv Interv Cardiol 2013;9:89-923.

10. Aguirre-Molina C, Garcia-Montes J A, Bialkowski J. Application of radiofrequency perforation to recanalization late stent thrombosis of aortic coarctation. Cathet Cardiovasc Interv 2011;78:428-31
11. SulikS, Fiszer R, Scalone G, Gomez-Monterrosas 0, Bialkowski J, Szkutnik M. Immediate and long term outcomes of native aortic coarctation and postsurgical aortic coarctation treated with stent implantation: a single center experience. Pol Arch Med Wew 2017;127:498-505.

12. Scalone G, Gomez-Monterrosas O, Fiszer R, Szkutnik M, Galeczka M, Bialkowski J. Combined strategy of Waterstone shunt percutaneous occlusion and medical treatment with sildenafil for management of pulmonary hypertension in adult patient with corrected tetralogy of Fallot. Adv Interv Cardiol 2017;3:277-8.

13. Szkutnik M, Menacho-Delgadillo R, Palmero-Zilveti E, Bialkowski J. Transcatheter closure of patent ductus arteriosus among native highaltitude habitants. Ped Cardiol 2008;29:624-627.

14. Bialkowski J, Glowacki J, Zabal C, Garcia-Montes A, et al. Patent ductus arteriosus at low and high altitudes: anatomical and haemodynamic features and their implications for transcatheter closure. Kardiol Pol 2011;69:431-436

15. Białkowski J. Interventional catheterization for congenital heart defects: what can we do for others? Project Rwanda. Adv Intev Cardiol 2019;15:385-6.

\section{ORCID}

Jacek Białkowski: 0000-0003-4276-0166

\section{CORRESPONDING AUTHOR Jacek Białkowski}

Department of Congenital Heart Diseases and Pediatric Cardiology, Silesian Center for Heart Diseases MC Skłodowskiej 9, 41-800, Zabrze, Poland tel. +48606488475

e-mail:jacek.bialkowski@gmail.com 